\title{
SEASONALITY AND DIEL ACTIVITY PATTERN OF GLOSSINA MORSITANS SUBMORSITANS (DIPTERA: GLOSSINIDAE) IN GHIBE RIVER VALLEY, SOUTHWEST ETHIOPIA
}

\author{
Merid Negash ${ }^{1}$, Melaku Girma ${ }^{2}$ and Emiru Seyoum ${ }^{1}$ \\ ${ }^{1}$ Department of Biology, Faculty of Science, Addis Ababa University, PO Box 1176 \\ Addis Ababa, Ethiopia. E-mail: meridenegash@yahoo.com \\ ${ }^{2}$ International Centre of Insect Physiology and Ecology, PO Box 17319, Addis Ababa, Ethiopia
}

\begin{abstract}
Aspects of the ecology of Glossina morsitans submorsitans inhabiting Ghibe River Valley was studied from October 2000 up to September 2001 with baited monoconical traps. The baits were acetone plus cow urine. Seasonality of the flies were investigated using baited monoconical traps by taking sample every month for five consecutive days for twelve months and diel activity pattern was investigated by taking sample every hour for three consecutive days. The density of G. m. submorsitans was found to be high during wet months and decrease during dry months. It was widely distributed during the rainy season in the savanna woodland; while its distribution was patchy during the dry season. G. m. submorsitans showed a bi-modal daily activity pattern with morning peak followed by mid day depression and then afternoon peak. Its activity rhythm showed a dual relation with temperature, positively correlated in the morning when the temperature is less than $30^{\circ} \mathrm{C}$ and negatively correlated when temperature is greater than $30^{\circ} \mathrm{C}$. Its relation with relative humidity was also both positively and negatively correlated at different time of the day.
\end{abstract}

Key words/phrases: Diel activity, Ghibe River Valley, G. m. submorsitans, seasonality, Southwest Ethiopia

\section{INTRODUCTION}

The tsetse flies are adapted to the wide range of habitats, from central African humid rain forests to the vast semiarid, open savannahs of eastern Africa. The total area infested by tsetse flies is between 8.5 and 10 million $\mathrm{km}^{2}$, which is more than $40 \%$ of the total land area of the infested countries (Moloo, 1993).

The general pattern of fluctuations in tsetse populations is roughly related to rainfall distribution throughout the year with a basic feature of an increase when rains start and a decrease during the dry season (Challier, 1982). Their pattern of distribution is a result of mainly climatic and biological factors.

For most species, the optimum temperature is about $25^{\circ} \mathrm{C}$, and higher or lower temperatures during particular seasons or development stages, limit their existence (Nagel, 1995). Long cold winters, often with frost, make conditions that are not suitable for tsetse. In cold weather, the fly cannot move about to feed. In cold soil, the pupa cannot complete its development before its stored food supplies are finished (FAO, 1982). Pupae of many species of tsetse require a humid (but not damp) soil in which to live. This probably limits the distribution of most species with the exception of some morsitans spp. and G. longipennis (FAO, 1982).

The occurrence of tsetse flies requires the presence of their host. Therefore, insufficient food may cause some areas to be with out tsetse, even though the areas may be suitable in other respects.

Vegetation such as trees, bushes, or thickets is required by tsetse as cover from the worst effects of a hot climate. Some species may prefer a particular type of vegetation. For example, the patchy distribution of Glossina austeni is in part due to the patchy distribution of humid evergreen thickets in which it lives. Tsetse flies are dependent on two different types of vegetation, one of which they use 
as their "home" and the other as their feeding ground. The first must have "furniture", such as fallen logs, hollows, overhanging rocks, or merely humus, which provides shelter. The second at least for morsitans must be open enough for the flies to see and attack game animals, cattle or human beings, on which they depend for what is apparently their sole food, which is blood (Swynnerton, 1936).

Most tsetse flies show one or two peaks of activity a day, depending on the prevailing environmental and biological factors (Crump and Brady, 1979). Tsetse flies are active by day. Morsitans groups are bimodal with morning and evening peak separated by a decline of activity at noon. This pattern is comparable to the activity of their hosts (Ford, 1971) and it is temperature dependent (Brady, 1973).

According to Langridge (1976) and Fuller (1978) five species of tsetse are found in Ethiopia. Glossina morsitans submorsitans, the most widely spread species, is found in river basins of Abay/Didessa, Baro/Akobo, and Omo/Ghibe. G. pallidipes, the second most widely spread species, is found in river basins of Baro/Akobo, Omo/Ghibe and Rift valley. G. tachinoides is encountered in Abay/Didessa and Baro/Akobo; G. fuscipes fuscipes in Baro/Akobo and Omo/Ghibe; and G. longipennis in restricted portions of the southern Omo/Ghibe basin. The area infested by these tsetse species is between 150,000-200,000 square kilometers of agriculturally productive landmass (ISCTRC, 1997).

Tsetse transmitted trypanosomosis is one of the major factors contributing to the sub-potential performance of livestock and lowered agricultural production in Ethiopia (Slingenbergh, 1992; ISCTRC, 1997). According to ISCTRC (1997), about ten million head of cattle and equivalent number of small ruminant and significant equine population are at the risk of acquiring trypanosomosis at any one time in Ethiopia. The associated annual estimated loss for Ethiopia is roughly US\$ 200 million in terms of mortality and morbidity losses in livestock, denied access to land resource for crop and livestock production, and in controlling the disease (IAEA, 1996).

G. m. submorsitans is the most widely spread tsetse species in Ethiopia and it is likely that this species is the most important vector. In south-west
Ethiopia, historical evidence suggests that an advance of G. m. submorsitans was responsible for a decrease in the area of cultivated land and associated settlement (Reid et al., 1997). In the Ghibe valley, where the present study was conducted, farmers claimed that a recent increase in trypanosomosis severity caused significant decreases in livestock population, contraction of farmlands and milk production (Reid et al., 1997). It was felt that knowledge of the daily activity and seasonal abundance of this particular sub species, G. m. submorsitans would be of fundamental importance to determine what time of the day and what month of the year to devise a management strategy against it. The main objectives of this study were to investigate the seasonality and diel activity of G. m. submorsitans.

\section{MATERIALS AND METHODS}

\section{Description of the study area}

The study was undertaken in the Ghibe valley in Southwest Ethiopia. The Ghibe River is a tributary of the Omo River, flowing into Lake Turkana on the Ethiopia/Kenya border. The valley base lies at an altitude of approximately $1100 \mathrm{~m}$. The area, in which the present study took place, referred as a Medale, is located at altitude of 1200-1260 meter above Sea level (masl), according to the map of the area described by Leak et al. (1993).

The climate is tropical with two rainfall periods a year. The main rainy season occurs between May and September, while the shorter season occurs in March and April. The area receives $900-1400 \mathrm{~mm}$ of rainfall on the average annually. The average annual maximum temperature ranges between $30^{\circ} \mathrm{C}$ and $37^{\circ} \mathrm{C}$, while the minimum ranges between $10^{\circ} \mathrm{C}$ and $15^{\circ} \mathrm{C}$ (Leak et al., 1993).

The majority of the land is covered with open grassland savanna. The dominant trees are Acacia seyal, Acacia sieberiana, and Acacia tortilis. The grass most encountered in the area are Hyperanium spp. and Sorghum spp. The soil of the study area is Vertisoil and light red clay (Reid et al., 1997). The different wild and domestic animals found in the study area include: Baboon monkey, warthog, bush pig, antelope, bushbuck, duiker, kudu, waterbuck, porcupine, hyena, other carnivores, and hippopotamus. Domestic animals in the study 
area include zebu cattle and goats. Biting flies that are common in the area include: Glossina morsitans submorsitans, G. pallidipes, G. f. fuscipes, Tabanidae and Stomoxinae.

\section{Seasonality of G. m. submorsitans}

For sampling Glossina morsitans submorsitans six monoconical traps (Laveissier and Grebaut, 1990) were used. The traps were set along transect from the acacia woodland in to open savanna grassland; sampling was taken every month for five consecutive days per month from October 2000 to September 2001. The cages from the traps were empty every 24 hours in the morning between 9 am and $10 \mathrm{am}$. The distance between traps was 200m (Steve, 1997). Each trap site was cleared of vegetation sufficiently to ensure reasonable visibility of the trap and dispersion of the odour attractants. Acetone plus cow urine was used as odour baits. The release rate of $500-600 \mathrm{mg} / \mathrm{hr}$ for acetone and $1-1.2 \mathrm{~g} / \mathrm{hr}$ for cow urine were applied (Vale et al., 1988).

The trap was based on the original model described by Laveissier and Grebaut (1990). The trap is a modified form of biconical trap, with the same upper mosquito net cone, but with three vertical panels of black and blue cloth hanging down at $120^{\circ}$ angles to each other instead of a cone, on the bottom half. The trap also has small cone that will be placed on the upper part of the large cone where metal cage covered with white netting will be kept. The lower part is freely open for flies' entrance. The trap was held in place by the metal pole, which passes through the wide opening. The lower part of the pole above the ground was greased to protect ants.

\section{Diel activity pattern of the fly}

The area where tsetse population is high was selected for studying daily activity patterns. The study was done for three consecutive days over four months period. For this six monoconical traps (Laveissier and Grebaut, 1990) were set up and the distance between the traps was $100 \mathrm{~m}$. The number of tsetse flies caught in the traps was recorded every hour from dawn to dusk. Catch was made only for clear days, with out rainfall and cloud, since the activity of tsetse flies are affected by weather condition of the area (Mohammed-Ahmed and Odulaja, 1997). Trap catches were collected at hourly interval from 0600 to $1800 \mathrm{hr}$. To evaluate the environmental determinants of activity, hourly temperature and relative humidity were simultaneously recorded using temperature and moisture sensor thermohygrometer model Intertronic TH-913H, at 30 minutes interval before the traps were emptied. The flies caught were killed by gently squeezing their thorax then identified, sexed and counted.

\section{Statistical analysis}

The data was analyzed using SPSS 10 for Windows (SPSS, 1998) standard version. The seasonal fluctuation of G. m. submorsitans was analyzed using one-way analysis of variance (ANOVA). The daily activity pattern of G. $m$. submorsitans was obtained by plotting the mean hourly catches \pm S.E. against hour of the day. Pearson correlation analysis was used to relate fly catch with temperature and relative humidity. Prior to analysis the hourly fly catch, temperature and relative humidity data were transformed to the logarithmic scale $\left(\log _{10}\right)$

\section{RESULTS}

\section{Seasonality}

G. m. submorsitans occurred with a monthly mean of $156.75 \pm 18.58$ (Fig. 2). Its population built up during the rainy periods. In the area there are two rainy periods, the long rainy period occurs from June to September and the short rainy period occurs from March to May. During the study G .m. submorsitans population peaked two times i.e., in January and during the rainy months May to September (Fig. 1). There was significant variation in population during the different months $(\mathrm{F}=8.571, \mathrm{df}, 11, \mathrm{P}=0.000)$. There was also a positive correlation between fly abundance and rainfall during the rainy season (Fig. 2); however, the relation was not significant $(\mathrm{r}=0.41, \mathrm{P}=0.186)$.

\section{Diel activity}

G. m. submorsitans showed a bi-modal activity (Fig. 3). The relation between fly activity and the prevailing temperature and relative humidity are shown in Table 1 . There was a positive correlation of fly activity with temperature up to $30^{\circ} \mathrm{C}$ and the relationship was significant $(\mathrm{r}=0.99, \mathrm{p}=0.001)$. 
However, when the temperature exceeded $30^{\circ} \mathrm{C}$ the relationship was negatively correlated $(\mathrm{r}=$ $0.824, p=0.023)$. The relationship between fly activity and relative humidity was negatively correlated in the morning $(\mathrm{r}=-0.982, \mathrm{P}=0.000)$ and positively correlated in the afternoon $(\mathrm{r}=0.837, \mathrm{P}=$ $0.000)$.

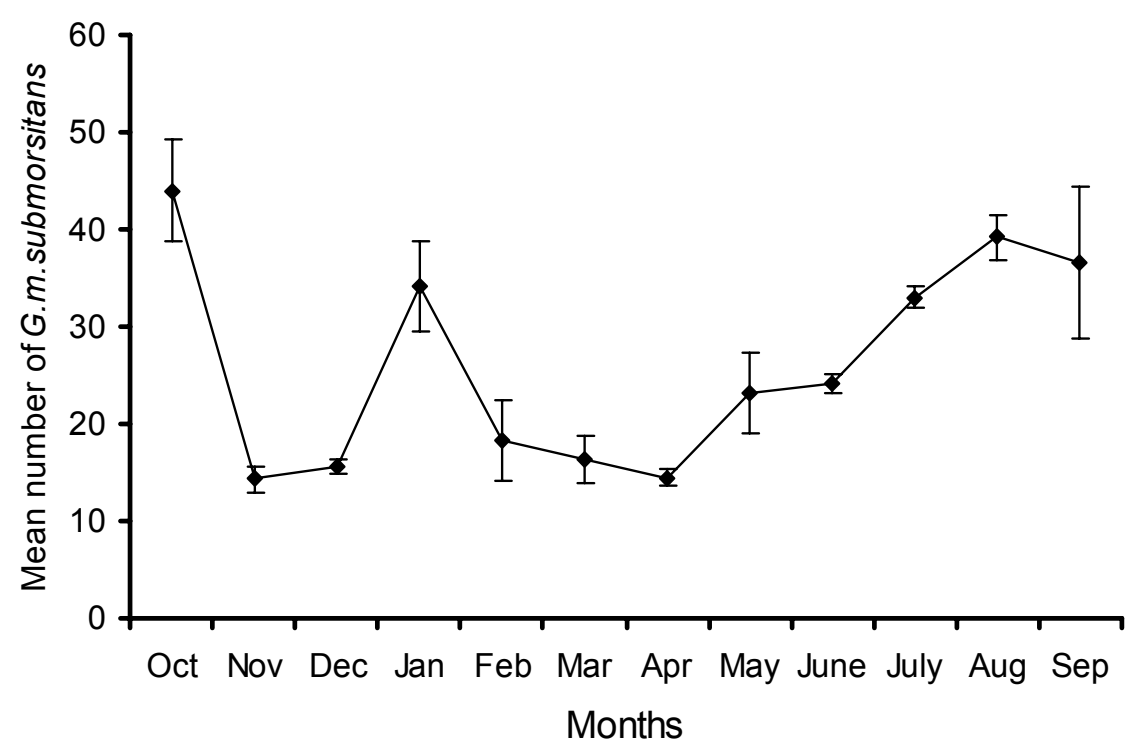

Fig. 1. Seasonality of G. m. submorsitans in the Ghibe river valley.

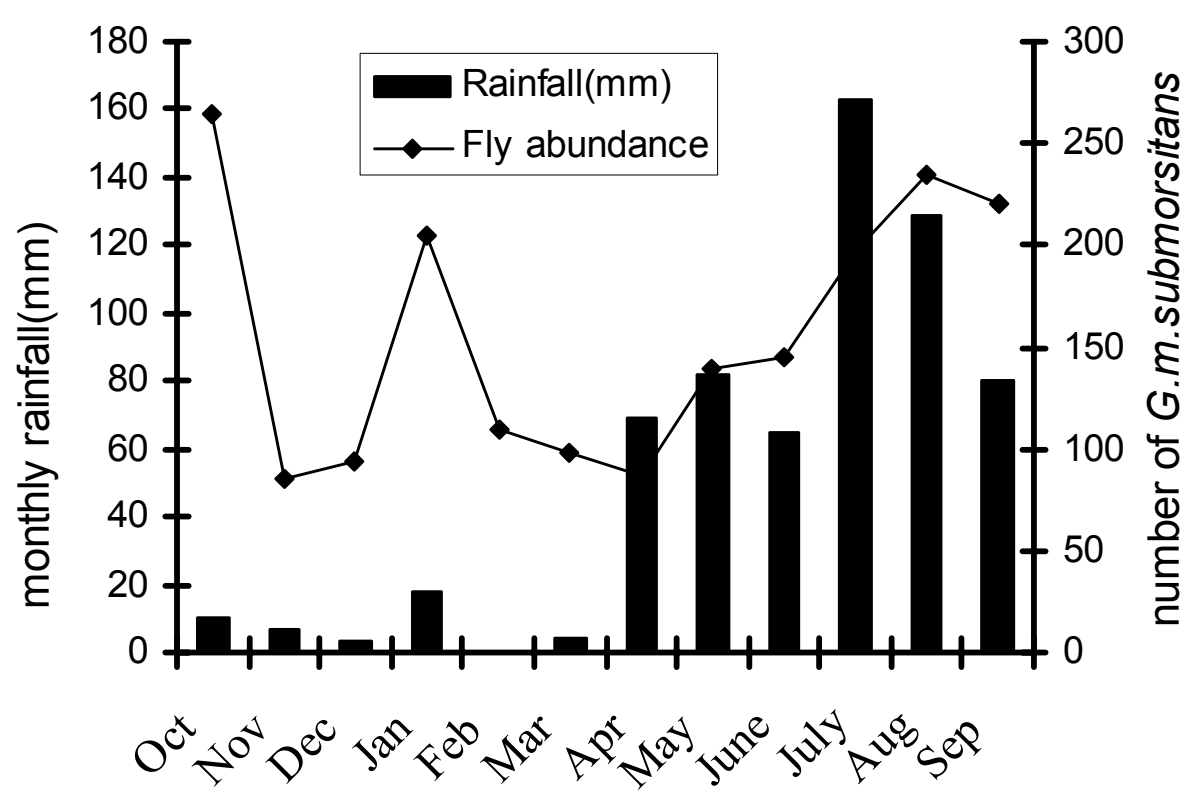

Months

Fig. 2. Relation between rainfall and fly abundance for the study period. 
Table 1. Correlation coefficients showing the relationships between fly activity with temperature and relative humidity in the morning (6-11) and afternoon (12-18).

\begin{tabular}{lcccc}
\hline \multicolumn{1}{c}{ Variable } & Hour & Temp. $\left({ }^{\circ} \mathrm{C}\right)$ and RH $(\%)$ & $\begin{array}{c}\text { Correlation } \\
\text { coefficient }\end{array}$ & P-value \\
\hline Temperature vs catch & $6-11$ & $19.38-29.88$ & 0.990 & 0.001 \\
Relative humidity vs catch & $6-11$ & $82.94-60.25$ & -0.982 & 0.000 \\
Temperature vs catch & $12-18$ & $33.84-26.69$ & -0.824 & 0.023 \\
Relative humidity vs catch & $12-18$ & $40.33-65.95$ & 0.837 & 0.000 \\
\hline
\end{tabular}

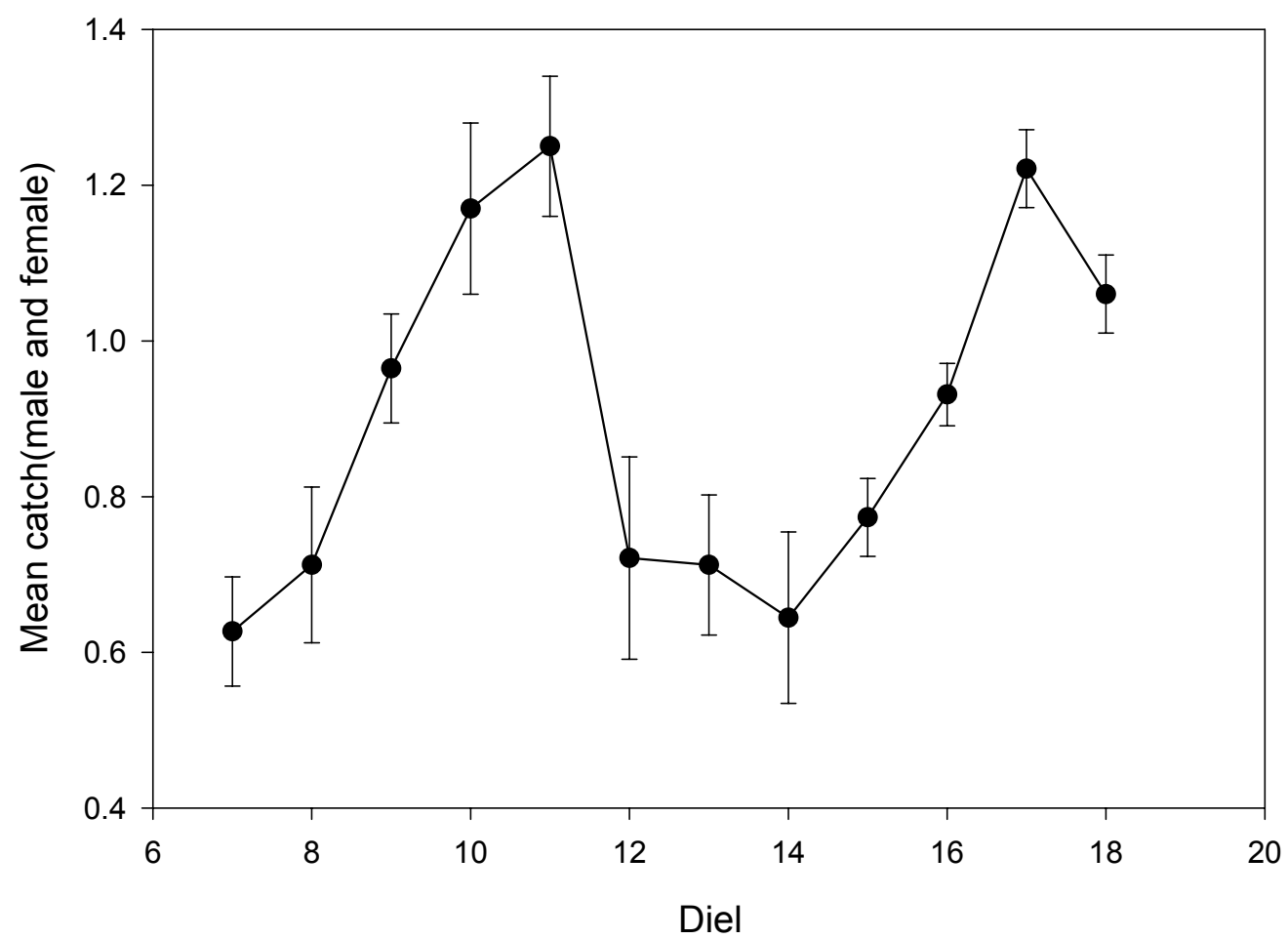

Fig. 3. Diel activity of G.m.submorsitans.

\section{DISCUSSION}

From the present investigation G. m. submorsitans were more abundant during the rainy months. Tsetse populations exhibit various patterns of population fluctuation related to local climates and vegetation. In general, pattern of fluctuations in tsetse populations is closely related to rainfall distribution throughout the year with a basic feature of an increase when rains start and a decrease during the dry season (Challier, 1982). In the present study G. m. submorsitans populations increased at the start of the rains to reach a peak of density 2-3 months later, and then declined as the dry season starts. The population of G. $m$. submorsitans built up started from May and continued up to October, which are rainy periods and then started declining from November to April, which are dry months. However, during January, which is a dry month, high number of $G$. $m$. submorsitans was caught. This may be due to immigration of G. m. submorsitans from the near by areas where bush fire was prevalent. As observed by Challier (1982), tsetse flies change their habitat to concentrate in the most suitable ones. There was also rain during this month, which may also be 
responsible for the high number of G. $m$. submorsitans encountered.

The relatively low density of G. m. submorsitans during the dry months may be due to an accelerated fat consumption presumably due to high temperature associated with the low moisture content of the soil, which adversely affects the development of the puparium (FAO, 1982).

It is not only the number of G. m. submorsitans, which was affected, but also their distribution fluctuated within a year. During the wet season, especially during July to early October, flies were widely distributed when the vegetation cover of the area rehabilitate, that provided them with shade and maintained a suitable microclimate, as well as a habitat for their vertebrate hosts. However, during the dry season they have restricted distribution. Their distribution was affected mostly by the rainfall and vegetation cover. Thus, flies were compelled to concentrate in restricted areas, which were most suitable for habitation.

Rainfall is known to affect puparial development directly and the eco-distribution of the fly and the mammalian hosts indirectly (FAO, 1982). The fact that the abundance of flies was positively correlated with rainfall (Fig. 2) indicates that the fly density increases as the rainfall increases. This is important for intensifying control program at periods when high percentage reduction is possible. Dransfield et al. (1990) found that for G. pallidipes $99 \%$ reduction can be obtained with baited traps during the dry season, however, the reduction was only $90 \%$ during the rainy season. Similarly, for G. tachinoides $90 \%$ reduction was observed during the dry season, but was not reduced at all during the rainy season mainly due to reinvasion.

With regard to daily activity G. m. submorsitans showed a bimodal activity pattern (Fig. 3). This result is in accordance with other works (Mulligan, 1970; Brady, 1973; Tesfa-Michael Tesfa-Yohannes, 1980; Turner, 1980; Getachew Tikubet, 1983). Both sexes reached peak during the same hours of the day. An endogenous circadian clock (Brady, 1972; 1975) controls spontaneous activity. Moreover, climatic factors influence the activity pattern to some extent (Brady and Crump, 1978). Starvation also has an enormous effect on activity (Barrass, 1970; Crump and Brady, 1979). Therefore, activity pattern may be unimodal or bimodal depending on whether optimal levels of abiotic and biotic factors have been exceeded or not, under particular circumstances.

There was a dual relation between the activity and temperature (Table 1). There was a positive correlation in the morning i.e., up to 11 am local time when the temperature was below $30^{\circ} \mathrm{C}$ and a negative correlation in the afternoon starting from 12 noon local time. This implies that the activity of G. $m$. submorsitans increased with a rise of temperature during the morning. This result agrees with that of Popham and Vickers (1979) who reported that tsetse flies are positively photo tactic below $30^{\circ} \mathrm{C}$. The morning peak is followed by mid day depression starting from 12 am up to $15 \mathrm{pm}$ local time when the temperature was $\geq$ $31^{\circ} \mathrm{C}$. At higher temperatures the flies begin to seek shade (Pilson and Pilson, 1967). During the afternoon, the fly number increased starting from $16 \mathrm{pm}$ local time, when the temperature was less than $30^{\circ} \mathrm{C}$.

Even though endogenous control such as hanger state, stress sexual desire (Crump and Brady, 1979) are the main component in determining the activity pattern of tsetse flies in nature, this can be modulated by environmental factors specially by temperature to make it uni or bi-modal such that activity correlates positively with temperature up to about $29^{\circ} \mathrm{C}$ but negatively above about $31^{\circ} \mathrm{C}$.

\section{CONCLUSION}

From the investigation it was clear that the reaction of G. m. submorsitans to abiotic and biotic factors is particularly important to their spatio-temporal distribution. There is a seasonal change in habitat and abundance. They are widely spread all over the savanna during the rainy season, but has restricted distribution during the dry season. They are also more abundant during the rainy season. Host abundance, vegetation cover, tsetse density might be important factors determining the degree of its spread. The main activity period is also dependent on temperature.

The Ghibe valley has great potential for sustainable agriculture if tsetse flies inhabiting the valley are controlled. It is also advisable to under take intervention program during the dry season 
when the flies are low in number and have restricted distribution. At the period of control limited area will be treated since tsetse habitat is patchy during this period. It would therefore not be necessary to cover the entire area if control measure is directed towards the vector. The low tsetse fly population can be controlled with continuous trapping.

\section{ACKNOWLEDGEMENTS}

The work was sponsored by African Regional Postgraduate Program in Insect Science. We thank Department of Biology of the Addis Ababa University and International Centre for Insect Physiology and Ecology, Ethiopia for their logistic support. Vestergaard Frandsen Group is acknowledged for providing us the tsetse traps. The National Meteorological Services Agency, provided meteorological data of the area.

\section{REFERENCES}

1. Barrass, R. (1970). The flight activity and settling behaviour of Glossina morsitans Westw. (Diptera: Muscidae) in laboratory experiments. Bulletin of Entomological Research 59:627-635.

2. Brady, J. (1972). The visual responsiveness of the tsetse fly Glossina morsitans Westw. (Glossinidae) to moving objects; the effects of hunger, sex, host odour and stimulus characteristics. Bulletin of Entomological Research 62:257-279.

3. Brady, J. (1973). The pattern of spontaneous activity in tsetse fly Glossina morsitans Westw. (Diptera: Glossinidae). Bulletin of Entomological Research 63:441-444.

4. Brady, J. (1975). 'Hunger' in the tsetse fly: the nutritional correlates of behaviour. Journal of Insect Physiology 21:807-829.

5. Brady, J. and Crump, A.J. (1978). The control of circadian activity rhythms in tsetse flies: environmental or physiological clock? Physiological Entomology 3:177-190.

6. Challier, A. (1982). The ecology of tsetse (Glossina spp.) (Diptera: Glossinidae). A review (19701981). Insect Science and its Applications 3(23):97-143.

7. Crump, A.J. and Brady, J. (1979). Circadian activity patterns in three species of tsetse fly: Glossina palpalis, G. austeni and G. morsitans. Physiological Entomology 4:311-318.
8. Dransfield, R.D., Brightwell, R., Kyorku, C. and Williams, B. (1990). Control of tsetse fly (Diptera: Glossinidae) populations using traps at Nguruman, South-west Kenya. Bulletin of Entomological Research 80:265-276.

9. FAO (1982). Tsetse Control Training Manual, Vol. 1, Tsetse Biology, Systematic and Distribution, Techniques, (Pollock, J.N., ed.) Food and Agriculture Organization of the United Nations, Rome, 280 pp.

10. Ford, J. (1971). The Role of Trypanosomosis in African Ecology. A Study of Tsetse Fly Problem. Clarendon press, Oxford, $568 \mathrm{pp}$.

11. Fuller, G.K. (1978). Distribution of Glossina in SouthWestern Ethiopia. Bulletin of Entomological Research 68:299-302.

12. Getachew Tikubet (1983). Studies on tsetse flies of Finchaa River Valley. MSc Thesis, School of Graduate Studies, Addis Ababa University, 83 pp.

13. IAEA (1996). Integrating the Sterile Insect Technique to Eradicate tsetse from the Southern Rift Valley of Ethiopia. Draft projects Document, International Atomic Energy Agency, Government of Federal Democratic Republic of Ethiopia.

14. ISCTRC (1997). International Scientific Council for Trypanosomosis Research and Control. 24th Meeting, OAU/STRC Publication, Maputo, No.119. pp. 77-81.

15. Langridge, W.P. (1976). A Tsetse and Trypanosomosis Survey of Ethiopia. Ministry of Overseas Development Report, MOD, 100 pp.

16. Laveissier, C. and Grebaut, P. (1990). Recherches sur les pieges a Glossines (Diptera: Glossinidae) mise au point d'un mode'le economique le piege 'Vavoua'. Tropical Medicine and Parasitology 41:185-192.

17. Leak, S.G.A., Woudyalew Mulatu, Authie, E., Peregrine, A.S., Rowlands, G.J. and Trail, J.C.M. (1993). Epidemiology of bovine trypanosomosis in the Ghibe Valley, south-west Ethiopia 1. Tsetse challenge and its relationship to trypanosome prevalence in cattle. Acta Tropica. 53:121-134

18. Mohammed-Ahmed, M.M. and Odulaja, A. (1997). Diel activity patterns and host preferences of Glossina fuscipes fuscipes (Diptera:Glossinidae) along the shores of lake Victoria, Kenya. Bulletin of Entomological Research 87:179-186.

19. Moloo, S.K. (1993). The distribution of Glossina species in Africa and their natural hosts. Insect Science and its Application 4:511-527. 
20. Mulligan, H.W. (ed.) (1970). The African Trypanosomosis. Ministry of Overseas Development and George Allen and Unwin, London, 950 pp.

21. Nagel, P. (1995). Environmental Monitoring Hand Book for Tsetse Control Operations. Margraf Verlag, 323 pp.

22. Pilson, R.D. and Pilson, B.M. (1967). Behavioural studies of Glossina morsitans Westw. in the field. Bulletin of Entomological Research 57:227-252.

23. Popham, E.J. and Vickers, H. (1979). Tsetse fly reactions to light and humidity gradients. Experientia 35:194-196.

24. Reid, R.S., Kruska, R.L., Muthui, N., Wotton, S., Wilson, C.J., Andualem Taye and Woudyalew Mulatu (1997). Distinguishing the impacts of change in trypanosomosis severity from other factors that cause land use change over time in southwestern Ethiopia. In: The 24th Meeting of the International Scientific Council for Trypanosomosis Research and Control. Maputo, Mozambique.

25. Slingenbergh, J. (1992). Tsetse control and agricultural development in Ethiopia. World Animal Review 1-2:30-36.
26. SPSS (1998). ). SPSS for Windows. Statistical software package, Version 10, SPSS Inc.

27. Steve, M. (1997). Practical trapping guidelines. In: Tsetse and Trypanosomosis Literature Notes. International Centre of Insect Physiology and Ecology, Nairobi, Kenya.

28. Swynnerton, C.F.M. (1936). The Tsetse Flies of East Africa: a First Study of their Ecology with a View to their Control. Trans. R. Ent. Soc. Lond. 84, 579 pp.

29. Tesfa-Michael Tesfa-Yohannes (1980). Preliminary ecological studies of Glossina morsitans (Glossinidae: Muscidae) in Didessa valley, Ethiopia. Ethiopian Journal of Agricultural Science 2:129-138.

30. Turner, D.A. (1980). Tsetse ecological studies in Nigeria and Mozambique. Resting behaviour. Insect Science and its Application 1:15-21.

31. Vale, G.A., Hall, D.R. and Gough, T.A.E. (1988). The olfactory response of tsetse flies, Glossina spp. (Diptera: Glossinidae) to phenols and urine in the field. Bulletin of Entomological Research 78:293300 . 